\title{
The Relationship between Elementary School Teachers' Work Motivation and Well-Being: The Mediating Effects of Principal Leadership and Work Stress
}

\author{
ByeolBee $\mathrm{Um}^{1}$, HyunGyung $\mathrm{Joo}^{2}$, \& DaYeon $\mathrm{Her}^{3}$ \\ ${ }^{1}$ Department of Elementary Counseling Education, Seoul National University of Education, Seoul, South Korea \\ ${ }^{2}$ Department of Graduate and Professional Studies, California State University, Sacramento, CA, USA \\ ${ }^{3}$ Department of Psychology, Miami University, Ohio, USA \\ Correspondence: ByeolBee Um, Department of Elementary Counseling Education, Seoul National University of \\ Education, Seoul, South Korea.
}

Received: November 12, 2018

Accepted: December 3, 2018

Available online: December 7, 2018

doi:10.11114/ijsss.v6i12.3762

URL: https://doi.org/10.11114/ijsss.v6i12.3762

\begin{abstract}
This research intends to examine the mediating effects of elementary school teachers' perception of principal leadership and work stress on the relationship between work motivation and well-being. For this purpose, the present study sampled 400 elementary school teachers from the Seoul metropolitan area in South Korea. Subsequently, the participants answered four scales to measure work motivation, perception of principal leadership, work stress, and well-being. The 324 data finally collected consist of 276 females and 48 males. The research results are as follows. First, four variables had significant correlations with each other, positively or negatively. Second, there was no significant mediating effect of principal leadership on work motivation and well-being. Third, teachers' work stress had a partial mediating effect on the relationship between work motivation and well-being. Fourth, principal leadership and work stress had a sequentially partial mediating effect on work motivation and well-being. This paper discusses these findings and then suggests the directions for future research.
\end{abstract}

Keywords: elementary school teachers, work motivation, well-being, principal leadership, work stress

\section{Introduction}

In recent years, the interest in teachers' well-being is rapidly emerging among educational researchers in South Korea. Perhaps such a trend could be the result of worrying about that teachers' well-being showed a sharp fall or the process of searching for a way to heighten it, emphasizing that their well-being is critical for children's well-being (Lee \& Cho, 2017; Jung, 2014; Lee, Kim, \& Kim, 2017; Park \& Son, 2011). Whatever the reason, given that teachers' well-being has a great influence on children's well-being, we require discussing their well-being seriously. Thanks to this realistic need, even though teachers' well-being tends to be magnifying as a hot issue in the educational field, it is unfortunate that most investigations are heavily skewed towards early childhood teachers' well-being (Lee \& Cho, 2017; Park \& Son, 2011). In particular, the point to notice here is that, contrary to a severe short of research on elementary school teachers' well-being, they, similar to early childhood teachers, also teach almost all subjects and spend most of the day with children (Lee, 2012; Park \& Son, 2011). Thus, we can expect that elementary school teachers' well-being also translates directly to students' well-being. Moreover, at this time when an upsurge in school violence is threatening the well-being of elementary school teachers rather than that of early childhood teachers in South Korea (Jung, 2014; Park \& Son, 2011; Shin, 2018), in-depth research on elementary school teachers' well-being is urgently required than ever before.

Though well-being is often considered the opposite state of ill-being (Kern, Waters, Adler, \& White, 2014), Seligman (2011) defined well-being as flourishing rather than just life satisfaction or the absence of negative function in the framework of positive psychology. Regarding well-being as flourishing after Seligman, Kern et al. (2014) selected PERMA model for assessing workplace well-being (Seligman, 2011) and then added negative emotion to teachers' well-being to include even the negative aspects in addition to the positive facets of the mental health spectrum. As a result, Kern et al. (2014) defined teachers' well-being as an aggregate of positive emotions, engagement, relationships, meaning, accomplishment, and negative emotions. To enhance teachers' well-being consisting of these six domains, 
first of all, we need to investigate factors contributing to elementary school teachers' well-being profoundly.

Many researchers directly or indirectly have suggested work motivation as a crucial factor contributing to well-being (Gillespie, 2009; Grant \& Shin, 2011; Nie, Chua, Yeung, Ryan, \& Chan, 2015; Peterson, Park, Hall, \& Seligman, 2009). Indeed, Gillespie (2009), Kanfer (2009), Nie et al. (2015), and Peterson et al. (2009) have maintained the perspective that the work motivation has positive impacts on well-being. Based upon these relevant works, we can expect that elementary school teachers' work motivation also leads to their well-being. Along with this perspective, given that zest, similar to high motivation, arouses psychological well-being (Park, Peterson, \& Seligman, 2004), it seems that teachers with high work motivation are more likely to feel well-being.

As noted earlier, though teachers' work motivation could directly contribute to their well-being, it is expected that principal leadership plays a critical role in the relationship between work motivation and well-being, because an elementary school is a kind of an organization. As such, we try to introduce teachers' perception of principal leadership as a variable mediating the relationship between work motivation and well-being. More specifically, teachers with high work motivation are expected to perceive principal leadership highly and seek help from a principal, considering the energetic and passionate aspects of work motivation (Bohns \& Flynn, 2010; Grant \& Shin, 2011; Park et al., 2004; Peterson et al., 2009). At the same time, teachers highly perceiving principal leadership tend to feel more well-being, owing to a respect consisting of perceived status and liking and a prosocial motivation meaning leader's desire to protect and promote the well-being of members (Grant \& Berg, 2011; Grant \& Shin, 2011; Huo \& Binning, 2008; Huo, Binning, \& Molina, 2010; Park et al., 2004; Peterson et al., 2009). Drawing on these previous studies, we can expect that teachers' perception of principal leadership mediates the relationship between work motivation and well-being positively.

In addition to teachers' perception of principal leadership, their work stress also might play a crucial role in the relationship between work motivation and well-being. Specifically, we can infer that work motivation, which evokes a directing, energizing, and maintaining effort, is powerful enough to ease work stress, as is shown in the evidence which can manage distress at work by reframing emotion as passion (Grant \& Shin, 2011; Wolf, Lee, Sah, \& Brooks, 2016). Thanks to such characteristics of work motivation (Bono, Glomb, Shen, Kim, \& Koch, 2013; Kim \& Nam, 2018; Grant \& Shin, 2011; Park, Bruno, \& Headrick, 2017; Park et al., 2004; Peterson et al., 2009; Wolf et al., 2016), teachers who hold a higher work motivation are less likely to perceive work stress. Simultaneously, it seems that teachers perceiving more work stress feel less well-being than do teachers perceiving less work stress (Park et al., 2017). Given these possibilities, there is a need to identify that work stress mediates the relationship between work motivation and well-being negatively.

Based upon discussion to date, we intend to examine the mediating effects of teachers' perception of principal leadership and work stress on the relationship between work motivation and well-being. Looking further ahead, we also try to identify a sequential mediating impact of principal leadership and work stress on the relationship between work motivation and well-being, in that high principal leadership perceived by teachers seems to result in less work stress. As an example, principals' prosocial motivation is expected to alleviate teachers' work stress by different ways including a respect (Batson, 1987; Grant, 2008; Grant \& Berg, 2011; Hendricks \& Payne, 2007; Huo \& Binning, 2008; Huo et al., 2010; O’Reilly, Caldwell, Chatman, Lapiz, \& Self, 2010; Schroeder \& Fishbach, 2015). As a consequence, there is the possibility that the higher principal leadership, the lower their work stress, which is predicted to relate to high well-being.

To summarize the earlier discussion, the purpose of this article is to examine whether teachers' perception of principal leadership and work stress partially mediate the relationship between work motivation and well-being, along with the sequential mediating effects of principal leadership and work stress. To achieve this purpose, we set the research model as Figure 1.

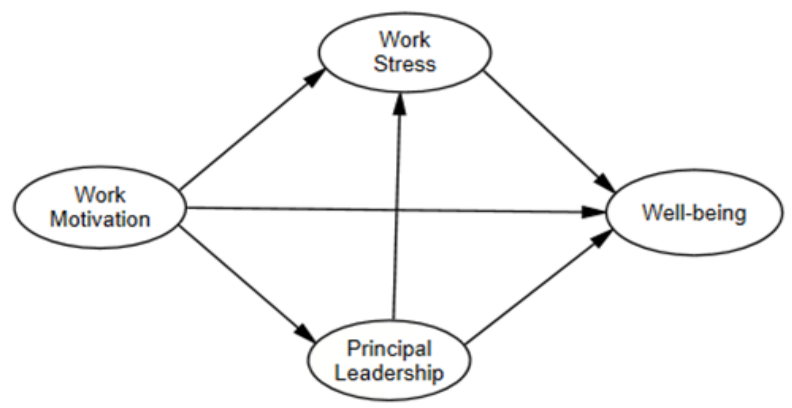

Figure 1. Research model 
This research model is a partial mediation model which combines the direct path from work motivation to well-being and three indirect paths. To put the indirect paths concretely, they include two paths going from work motivation through principal leadership or work stress to well-being and one path passing from work motivation through sequentially principal leadership and work stress to well-being. The hypotheses to specify this research model are as follows.

Hypothesis 1. There would be significant correlations between elementary school teachers'work motivation, well-being, principal leadership, and work stress, respectively.

Hypothesis 2. Elementary school teachers' perception of principal leadership would have a partial mediating effect on their work motivation and well-being.

Hypothesis 3. Elementary school teachers' work stress would have a partial mediating effect on their work motivation and well-being.

Hypothesis 4. Elementary school teachers' perception of principal leadership and work stress would have a sequentially partial mediating effect on their work motivation and well-being.

\section{Method}

\subsection{Participants}

Using convenience sampling, we selected 400 elementary school teachers working in the Seoul metropolitan area in South Korea and then administered four instruments to them. Out of 361 data collected from them, 30 with missing values and 7 with insincere responses were excluded. As a result, the final data analyzed are 324 samples which consist of 276 females $(85.2 \%)$ and 48 males (14.8\%). This high gender ratio of female elementary school teachers falls within the total gender ratio of female elementary school teachers in the Seoul metropolitan area, ranging from $79.7 \%$ to $86.7 \%$ (Korean Educational Development Institute, 2017). There are 166 (51.2\%) teachers in their 20-30's and 154 (47.5\%) in their 40-50's, whereas 4 (1.2\%) over their 60's.

\subsection{Scales}

All instruments used in this research are the 4-point Likert scales from 1 (strongly disagree) to 4 (strongly agree). The higher score in each measure indicates that teachers have more work motivation, work stress, and well-being in elementary school, and perceive principal leadership more highly. Before yielding scores, some items were reversely coded.

\subsubsection{Work Motivation}

To measure elementary school teachers' work motivation, we used a 16-item scale consisting of a desire to learn (8 items) and mastery goals (8 items). To be more specific, we selected the Motivational Trait Questionnaire (Short Form) (Heggestad \& Kanfer, 2000) and then translated just two subscales among six subscales into Korean which were found to be suitable for South Korean elementary school teachers. Cronbach's $\alpha$ coefficient of this scale is .897 and .756 for each subscale, and .880 for the total scale. As a result of performing the confirmatory factor analysis after setting covariances among error terms, the fit indices of the scale indicated satisfactory or acceptable fit (NFI=.902, TLI=.918, CFI=.939, RMSEA=.066). The examples of items are as follows: "When I become interested in something, I try to learn as much about it as I can (a desire to learn)" and "I set high standards for myself and work toward achieving them (mastery goals)."

\subsubsection{Well-being}

Teachers' well-being was measured using the Multidimensional Scale of Well-being developed by Kern et al. (2014). Since two items in positive emotions from a total of 36 items were deleted, with performing confirmatory factor analysis, the scale consists of a 34-item with six subscales: positive emotions (4 items), engagement (6 items), relationships (6 items), meaning (5 items), accomplishment (7 items), and negative emotions (6 items). Cronbach's $\alpha$ coefficient of this scale is .950 for the total scale and ranges from .825 to 939 for the subscales. In the confirmatory factor analysis, the goodness of fit of the scale was satisfactory or acceptable (NFI=.902, TLI=.938, CFI=.944, RMSEA=.053). There are items such as "Enthusiastic (positive emotions)," "My work inspires me (engagement)," "We care for fellow employees who are struggling (relationships)," "My life has a clear sense of purpose (meaning)," "I am doing just as well as my peers (accomplishment)," and "Nervous (negative emotions)."

\subsubsection{Principal Leadership}

To measure principal leadership, we used the Authentic Leadership Scale of Avolio and Gardner (2005). Since teachers answered on this principal leadership scale, principal leadership in the current study means the principal leadership perceived by teachers. To be specific, we used 14 items after removing two items in transparency subscale among four 
subscales through confirmatory factor analysis. The 14-item scale consists of four subscales including transparency (3 item), moral/ethical (4 item), balanced processing ( 3 item), and self-awareness (4 item). Cronbach's $\alpha$ coefficient of this scale is .936 for the whole scale and is between .721 and .872 for the subscales. In the confirmatory factor analysis after setting covariances among error terms, the fit indices of the scale indicated good or acceptable fit (NFI=.944, TLI=.945, CFI=.961, RMSEA=.079). Following the authors' guideline which allows researchers to release up to three items, only three examples of items are as follow: "The principal encourages everyone to speak their mind (transparency)," "The principal demonstrates beliefs that are consistent with actions (moral/ethical)," and "The principal accurately describes how others view his or her capabilities (self-awareness)."

\subsubsection{Work Stress}

For assessing teachers' work stress, the scale is a 14-item instrument divided into four subscales: interpersonal conflict (3 items), the occupational system (4 items), lack of reward ( 3 items), and occupational climate (4 items). The questions were taken from the Korean Occupational Stress Scale (Chang \& Koh, 2005), which is suitable for South Korean elementary school teachers. Cronbach's $\alpha$ coefficient of the scale ranges from .835 to .756 for the subscales and is .880 for total scale. In the confirmatory factor analysis after setting covariances among error terms, the fit indices showed satisfactory or acceptable fit (NFI=.905, TLI=.917, CFI=.943, RMSEA=.062). The examples of items are like "The fellow teachers are cooperative in my work (interpersonal conflict)," "I can reflect my thought on my work including classes (occupational system)," "I have the opportunity to develop and demonstrate my ability (lack of reward)," and "The atmosphere of the school is authoritative and vertical (occupational climate)."

\section{Results}

\subsection{Descriptive Statistics and Correlation Coefficients}

Descriptive statistics for work motivation, well-being, principal leadership, and work stress and Pearson's correlation coefficients between them are presented in Table 1. Table 1 shows the means, standard deviations, skewness, and kurtosis at the bottom. It turned out that the assumption of normality was met since the absolute values of skewness and kurtosis were less than three and seven, respectively. Subsequently, the correlations between major variables are as follows. First, all relationships between the work motivation, well-being, and principal leadership were significantly positive $(r=.224 \sim .486, p<.01)$, which mean that teachers with the higher work motivation and principal leadership are prone to show the higher level of well-being. Second, work stress negatively related to work motivation, principal leadership, and well-being $(r=-.212 \sim .652, p<.05)$. This result shows a possibility that the higher teachers' work stress, the lower their work motivation, well-being, and the perception of principal leadership.

Table 1. Descriptive statistics and correlation coefficients of major variables

\begin{tabular}{|c|c|c|c|c|}
\hline Variable & 1 & 2 & 3 & 4 \\
\hline 1. Work motivation & 1 & & & \\
\hline 2. Well-being & $.486^{* *}$ & 1 & & \\
\hline 3. Principal leadership & $-.212^{* *}$ & $-.652^{* *}$ & 1 & \\
\hline 4. Work stress & $.224^{* * *}$ & $.343^{* *}$ & $-.469^{* *}$ & 1 \\
\hline$M$ & 3.124 & 3.087 & 2.910 & 2.005 \\
\hline$S D$ & 6.045 & 13.229 & 7.033 & 5.063 \\
\hline Skewness & .286 & -.167 & -.167 & .354 \\
\hline Kurtosis & -.468 & 1.389 & .375 & 2.258 \\
\hline
\end{tabular}

$* p<.05, * * p<.01$.

Before verifying research model fit, according to the two-step approach (Anderson \& Gerbing, 1988), firstly, the confirmatory factor analysis on the measurement model was implemented after parceling items, averaging the items scores in each sub-variable of latent variables. To evaluate measurement model, we examined the goodness of fit indices instead of the chi-square statistic because chi-square statistic assumes multivariate normality and is sensitive to sample size (Hooper, Coughlan, \& Mullen, 2008). In result, as presented in Table 2, the values of the Normed Fit Index (NFI), the Tucker-Lewis Index (TLI), and the Comparative Fit Index (CFI) showed greater than .90, indicating a good fit of the model. Also, the value of the Root Mean Square Error of Approximation (RMSEA) was .078 (<.080), representing an acceptable fit (Cudeck \& Browne, 1993).

Table 2. The goodness of fit of the measurement model

\begin{tabular}{llllllr}
\hline Model & $D f$ & $P$ & NFI & TLI & CFI & RMSEA \\
\hline $\begin{array}{l}\text { Measurement } \\
\text { model }\end{array}$ & 95 & .000 & .900 & .913 & .931 & .078 \\
\hline
\end{tabular}


Subsequently, as shown in Figure 2 and Table 3, we yielded the standardized factor loadings, the average variance extracted (AVE), and the construct reliability (CR) of the measurement model. First, the standardized factor loadings of measurement model ranged from .538 to .903 , implying that they are significant. Second, as AVEs ranged from .641 to .779 and CRs were from .871 to .934 , the convergent validity was established. Third, compared AVEs with the squares of correlation coefficients, the lowest AVE was bigger than the square of the highest correlation coefficient between work stress and well-being $(.641>.640)$, showing the discriminant validity. In sum, it is shown that the measured variables of work motivation, principal leadership, work stress, and well-being validly measure the latent variables respectively.

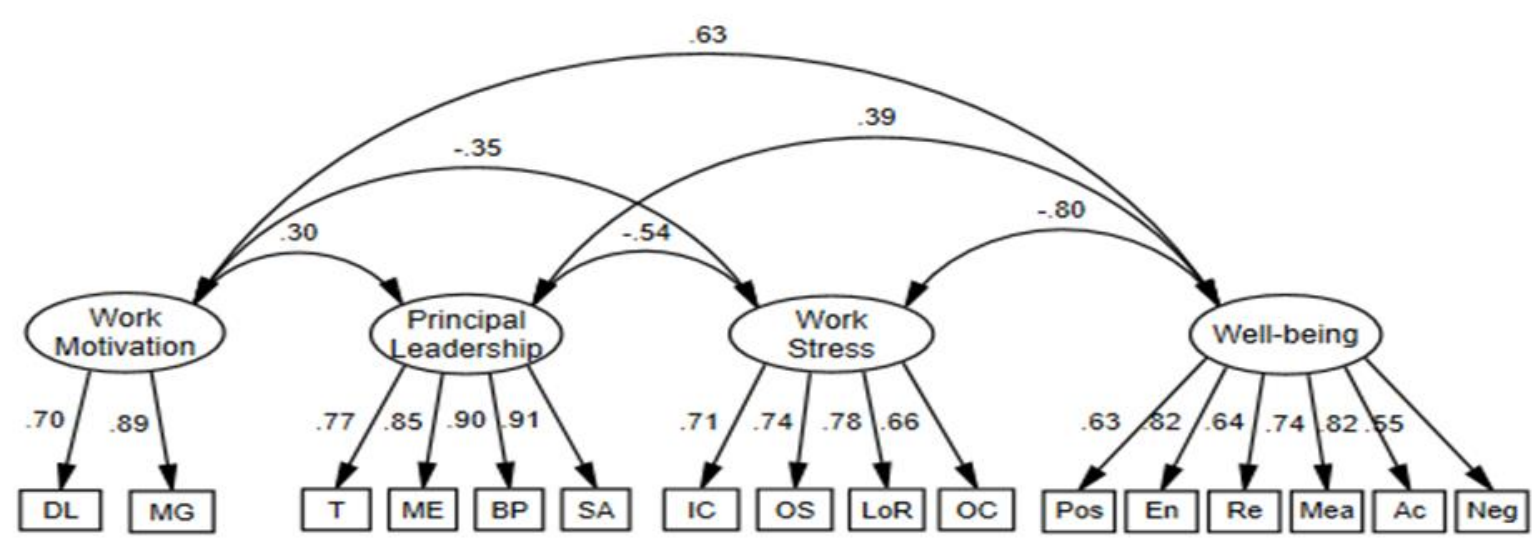

Figure 2. Measurement model

Table 3. Factor loadings of the measurement model

\begin{tabular}{|c|c|c|c|c|c|c|c|}
\hline $\begin{array}{l}\text { Latent } \\
\text { variable }\end{array}$ & Observed variable & $\begin{array}{l}\text { Unstandardized } \\
\text { factor loadings }\end{array}$ & $\begin{array}{l}\text { Standardized } \\
\text { factor loadings }\end{array}$ & SE & $\begin{array}{l}\text { Critical } \\
\text { Ration }\end{array}$ & AVE & $\begin{array}{l}\text { Construct } \\
\text { Reliability }\end{array}$ \\
\hline $\begin{array}{l}\text { Work } \\
\text { motivation }\end{array}$ & $\begin{array}{l}\text { Desire to learn } \\
\text { Mastery goals }\end{array}$ & $\begin{array}{l}1.000 \\
1.133 \\
\end{array}$ & $\begin{array}{l}.694 \\
.886 \\
\end{array}$ & .119 & $9.350^{* * * *}$ & .776 & .871 \\
\hline Well-being & $\begin{array}{l}\text { Positive emotions } \\
\text { Engagement } \\
\text { Relationships } \\
\text { Meaning } \\
\text { Accomplishment } \\
\text { Negative emotions }\end{array}$ & $\begin{array}{l}1.000 \\
2.089 \\
1.623 \\
1.599 \\
2.194 \\
1.676 \\
\end{array}$ & $\begin{array}{l}.612 \\
.805 \\
.623 \\
.720 \\
.807 \\
.538 \\
\end{array}$ & $\begin{array}{l}.094 \\
.107 \\
.084 \\
.106 \\
.131 \\
\end{array}$ & $\begin{array}{l}11.983^{* * * *} \\
9.177^{* * *} \\
10.183^{* * * *} \\
10.928^{* * * *} \\
7.927^{* * * *}\end{array}$ & .641 & 913 \\
\hline $\begin{array}{l}\text { Principal } \\
\text { leadership }\end{array}$ & $\begin{array}{l}\text { Transparency } \\
\text { Moral/Ethical } \\
\text { Balanced processing } \\
\text { Self-awareness } \\
\end{array}$ & $\begin{array}{l}1.000 \\
1.288 \\
1.212 \\
1.481 \\
\end{array}$ & $\begin{array}{l}.766 \\
.845 \\
.893 \\
.903 \\
\end{array}$ & $\begin{array}{l}.069 \\
.072 \\
.087 \\
\end{array}$ & $\begin{array}{l}18.533^{* * * *} \\
16.946^{* * * *} \\
17.103^{* * *}\end{array}$ & .779 & 934 \\
\hline Work stress & $\begin{array}{l}\text { Interpersonal conflict } \\
\text { Occupational system } \\
\text { Lack of reward } \\
\text { Occupational climate }\end{array}$ & $\begin{array}{l}1.000 \\
1.314 \\
1.215 \\
1.408 \\
\end{array}$ & $\begin{array}{l}.713 \\
.735 \\
.782 \\
.657 \\
\end{array}$ & $\begin{array}{l}.087 \\
.073 \\
.109 \\
\end{array}$ & $\begin{array}{l}15.188^{* * * *} \\
16.658^{* * *} \\
12.922^{* * *}\end{array}$ & .700 & 903 \\
\hline
\end{tabular}

$* * p<.01, * * * p<.001$.

\subsection{Verification of the Research Model}

To examine the partial mediating effects of principal leadership and work stress on the relationship between work motivation and well-being, we tested the goodness of fit of this research model. As a result of identifying the goodness of fit, the fit indices such as NFI, TLI, and CFI were above .90, implying a good fit, and RMSEA was .74, revealing an acceptable fit in Table 4.

Table 4. The goodness of fit of the research model

\begin{tabular}{llllllr}
\hline Model & $D f$ & $p$ & NFI & TLI & CFI & RMSEA \\
\hline $\begin{array}{l}\text { Measurement } \\
\text { model }\end{array}$ & 92 & .000 & .909 & .920 & .939 & .074 \\
\hline Padh
\end{tabular}

Path coefficients of the research model are shown in Table 5 and Figure 3. The all coefficients of the path from work motivation to well-being $(\beta=.401, p<.001)$, the path from work motivation to principal leadership $(\beta=.275, p<.001)$ and the path from work motivation to work stress $(\beta=-.218, p<.01)$ were significant. Also, both the path from principal leadership to work stress $(\beta=-.434, p<.001)$ and the path from work stress to well-being $(\beta=-.594, p<.001)$ showed 
significant coefficients excluding the path from principal leadership to well-being $(\beta=-.083, p>.05)$.

Table 5. Path coefficients of the research model

\begin{tabular}{lcccc}
\hline \multicolumn{1}{c}{ Path } & $\mathrm{B}$ & $\beta$ & SE & Critical Ratio \\
\hline Work motivation $\rightarrow$ Well-being & .271 & .401 & .040 & $6.770^{* * * *}$ \\
Work motivation $\rightarrow$ Principal leadership & .155 & .275 & .036 & $4.294^{* * *}$ \\
Work motivation $\rightarrow$ Work stress & & & & $-3.288^{* *}$ \\
Principal leadership $\rightarrow$ Well-being & -.069 & -.218 & .021 & -1.482 \\
Principal leadership $\rightarrow$ Work stress & -.099 & -.083 & .067 & $-5.966^{* * *}$ \\
Work stress $\rightarrow$ Well-being & -.244 & -.434 & .041 & $-7.132^{* * *}$ \\
\hline
\end{tabular}

$* * p<.01, * * * p<.001$.

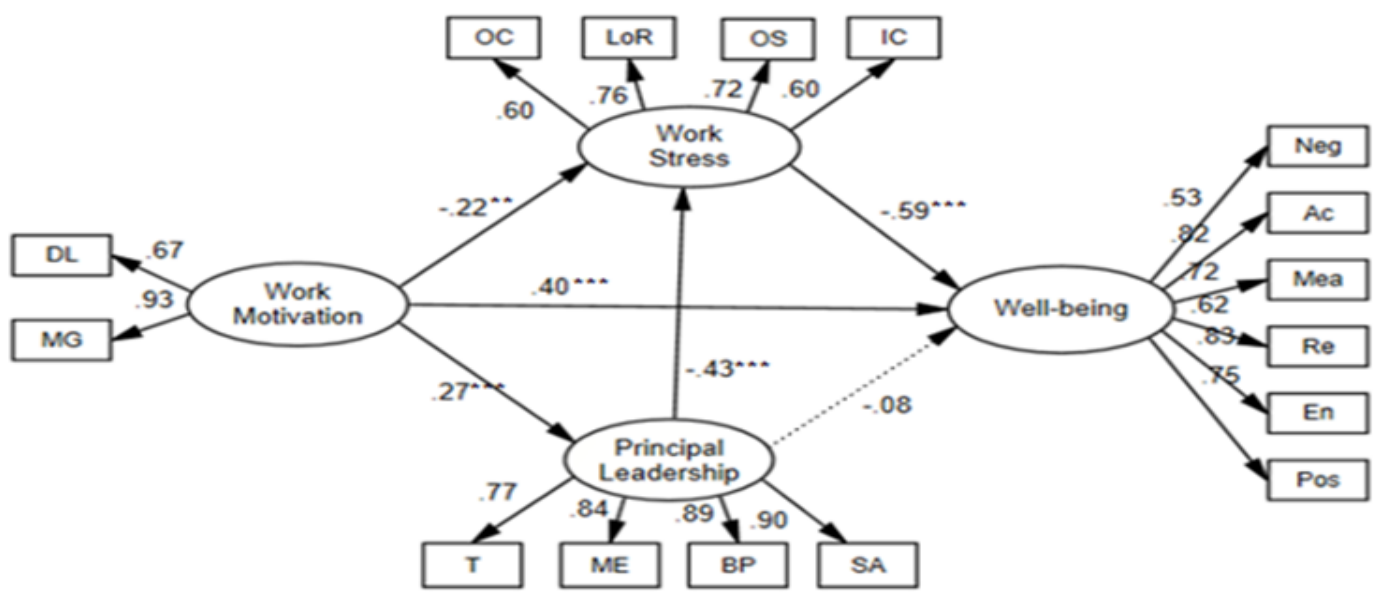

Figure 3. Structural equation model

Note. Values represent standardized path coefficients. The dotted line from principal leadership to well-being indicates the nonsignificance of the path. $* * p<.01, * * * p<.001$.

The results of analyzing the direct, indirect, and total effect of main variables are presented in Table 6 . Firstly, the direct effect of elementary teachers' work motivation on well-being was .401, and the indirect effect of work motivation on well-being mediated by principal leadership and work stress was .195. Since the indirect effect includes the effects of two paths, we used phantom variables to identify each indirect effect. In result, the indirect effect of the path from work motivation through work stress to well-being was .129, and the indirect effect of the other from work motivation through sequentially principal leadership and work stress to well-being was .068. Consequently, the total effect encompassing the direct effect of work motivation on well-being and the indirect effects such as the mediating effect of work stress and the sequential mediating effect of principal leadership and work stress showed .596. Besides, the direct effect of principal leadership on well-being was -.08 and the direct effect of work stress on well-being indicated -.594, and the direct effect of principal leadership on work stress showed -.434 while the indirect effect of principal leadership on well-being was .254.

Table 6. Direct, indirect, and total effect between main variables

\begin{tabular}{lllll}
\hline Predicting variable & Criterion variable & Direct effect & Indirect effect & Total effect \\
\hline Work motivation & Well-being & .401 & .195 & .596 \\
& Principal leadership & .275 & -.116 & .275 \\
Principal leadership & Work stress & -.218 &. .334 & .246 \\
& Well-being & -.080 &. .434 & -.434 \\
Work stress & Work stress & -.594 & & -.594 \\
\hline
\end{tabular}

To confirm the statistical significance of mediating effects, we utilized the bootstrapping method. Since AMOS provides bootstrapping for a single total mediating effect even when the model has multiple mediators, this research introduced phantom variables. For estimating, 2,000 samples were created by random sampling from the raw data $(N=324)$. As presented in Table 7, the two mediating effects were significant since zero exists within the $95 \%$ confidence intervals of the paths from work motivation to well-being through work stress (.086 .160) and sequentially principal leadership and work stress (.036 .120). In contrast, zero falls within the 95\% confidence intervals of the path from work motivation to well-being through principal leadership (-.046 .161). 
Table 7. Verification of each mediating effect

\begin{tabular}{|c|c|c|c|c|c|}
\hline \multirow{2}{*}{ Path } & \multirow{2}{*}{ B } & \multirow{2}{*}{ SE } & \multicolumn{2}{|c|}{$95 \% \mathrm{CI}(\mathrm{BC})$} & \multirow[t]{2}{*}{$p$} \\
\hline & & & lower & upper & \\
\hline $\begin{array}{l}\text { Work motivation } \rightarrow \text { Principal leadership } \rightarrow \\
\text { Well-being }\end{array}$ & .049 & .046 & -.046 & .161 & .304 \\
\hline $\begin{array}{l}\text { Work motivation } \rightarrow \text { Work stress } \rightarrow \\
\text { Well-being }\end{array}$ & $.122^{* * *}$ & .019 & .086 & .160 & .001 \\
\hline $\begin{array}{l}\text { Work motivation } \rightarrow \text { Principal leadership } \rightarrow \\
\text { Work stress } \rightarrow \text { Well-being }\end{array}$ & $.071^{* * * *}$ & .015 & .036 & .120 & .001 \\
\hline
\end{tabular}

$* * p<.01, * * * p<.001$.

As discussed earlier, the results supported three out of four hypotheses set in the current study. To be specific, first, all the relationships between major variables are significant. Second, there is no significant mediating effect of principal leadership on the relationship between work motivation and well-being. Third, work stress has a partial mediating effect on the relationship between work motivation and well-being. Fourth, principal leadership and work stress have a sequentially partial mediating effect on the relationship between work motivation and well-being.

\section{Discussion}

The present research was intended to confirm the mediating effects of elementary school teachers' perception of principal leadership and work stress on the relationship between work motivation and well-being. We set four hypotheses to reach this purpose, and three of four hypotheses were supported, except hypothesis 2, namely, a perception of principal leadership would have a partial mediating effect on their work motivation and well-being. Specifically, all the correlations between major variables were significant, and work stress had a partial mediating effect on the relationship between work motivation and well-being, and principal leadership and work stress had a sequentially partial mediating effect on that. In contrast, there was no significant mediating effect of principal leadership on work motivation and well-being. These results are discussed with previous studies as follows.

First of all, there were all significant relationships between elementary school teachers' work motivation, principal leadership, work stress, and well-being, positively or negatively. Concretely, work motivation had significant positive correlations with principal leadership and well-being, which means that the higher teachers' work motivation, the higher principal leadership and well-being. To be more specific, the positive relationship between work motivation and well-being was parallel to the perspectives of Gillespie (2009), Kanfer (2009), Nie et al. (2015), and Peterson et al. (2009) that work motivation affects well-being. In other words, teachers with higher work motivation are more likely to feel well-being because people holding the high work motivation tend to put the energetic and positive spin on life (Grant \& Shin, 2011; Park et al., 2004; Peterson et al., 2009).

Besides, the finding that work motivation had a positive connection with principal leadership is consistent with the research of Davis and Wilson (2000). Perhaps this evidence is due to that the high work motivation relates to teachers' positive approach to principal leadership, like that zest makes people take a positive approach to life with anticipation, energy, and excitement (Peterson et al., 2009).

Teachers' perception of principal leadership also was positively correlated with their well-being. This result is in line with the research result of Cho and Lee (2017), indicating a significant positive relationship between early childhood teachers' perception of directors' servant leadership and teachers' happiness. However, it contrasts with the finding of Oh, Roh, Kang, and Suh (2015), reporting no significant correlation between employers' transformative leadership and employees' happiness. As such, it requires precisely examining the inconsistent relationships between principal leadership and their well-being.

On the other hand, work stress negatively related to work motivation, well-being, and principal leadership. This evidence backs up the relevant investigations that work stress has the significant negative associations with work motivation (Grant, 2008), well-being (Kim \& Nam, 2018; Park et al., 2017; Wang, Hernandez, Newman, He, \& Bian, 2016), and principal leadership (Kwon, 2012). These findings allow us to infer that the higher teachers' work stress, the lower their work motivation, principal leadership, and well-being. More specifically, given the negative relationship between work stress and work motivation (Grant, 2008; Peterson et al., 2009), there is a possibility that teachers with high work motivation are less likely to perceive work stress, of course, although teachers who highly perceive work stress may reveal less work motivation.

Likewise, work stress was negatively connected to well-being. This result seems to be natural in that excessive stress leads to negative emotion influencing well-being adversely (Kern et al., 2014; Wang et al., 2016). Further, it implies that work stress tends to result in burnout on the opposite of well-being (Park et al., 2017), unless work stress is relieved by positive reflection, reframing, micro-break activities, or effort-recovery approach (Bennett, Gabriel, Calderwood, 
Dahling, \& Trougakos, 2016; Bono et al., 2013; Kim, Park, \& Niu, 2017; Wang et al., 2016; Wolf et al., 2015).

Work stress had a negative connection to principal leadership, too. This finding indicates that though teachers with high work stress may perceive principal leadership poorly, teachers who highly perceive principal leadership tend to feel less work stress, owing to the prosocial motivation and respect of leader (Grant, 2008; Huo \& Binning, 2008).

As shown above, though all the significant correlations between work motivation, principal leadership, work stress, and well-being help us to understand predictive relationships between major variables, it cannot clarify the delicate relationship among them. As a result of introducing the structural equation model to clarify it, the findings showed that the direct path from work motivation to well-being and two indirect paths are significant, except for one indirect path. Concretely, work stress had a partial mediating effect on the relationship between work motivation and well-being, and principal leadership and work stress had a sequentially partial mediating effect on that. On the contrary, there was no significant mediating effect of principal leadership on work motivation and well-being.

In more detail, the first path that goes from work motivation to well-being revealed a significant effect, and this finding supports the positions of Gillespie (2009), Kanfer (2009), Nie et al. (2015), and Peterson et al. (2009). These findings imply that elementary school teachers' work motivation has a significant contribution to well-being. The reason is that teachers with high work motivation tend to find well-being, given that the zest results in psychological well-being (Park et al., 2004). Moreover, the traits of participants in the current work seem to play a crucial role in bringing out such evidence. Specifically, it relates to the system in which South Korea trains elementary school teachers. To be more specific, since South Korea has a dozen of public universities to train only elementary school teachers and appoints elementary school teachers among people graduating from one of them, they may regard teaching itself as the most rewarding and a pivotal part of their existence. According to Park et al. (2004), Peterson et al. (2009), and Wrzesniewski, McCauley, Rozin, and Schwartz (1997), people holding such traits not only show higher work motivation but also feel more well-being. Thanks to such traits, in consequence, it seems that elementary school teachers hold high work motivation and, in turn, lead to high well-being.

The second path which goes from teachers' work motivation through principal leadership to well-being was not significant. In detail, unlike the first part of the path from work motivation to principal leadership, the second part of the path from principal leadership to well-being was not significant. In the opposite of the hypothesis, this result is supposed to relate to the kind of principal leadership in that a different kind of leadership may yield different results (Lee \& Cho, 2017; Oh et al., 2015). Accordingly, perhaps this finding is due to using the authentic leadership scale falling short of caring and promoting factors that may influence on well-being.

The third path which passes from teachers' work motivation to well-being through work stress had a significant effect. Little is known about a study backing up this result directly, but it is explainable through precedent works indirectly. Above all, the negative path from teachers' work motivation to work stress is indirectly supported by findings regarding other groups (Bono et al., 2013; Kim \& Nam, 2018; Grant \& Shin, 2011; Park et al. 2004; Park et al., 2017; Peterson et al., 2009; Wolf et al., 2016). In more detail, the trait of work motivation which is directing and energizing (Grant \& Shin, 2011) seems to contribute to this finding that teachers with high work motivation perceive work stress less. Also, this finding is in line with the result of precedent work that learning instead of relaxing decreases deviance in the face of work stressors (Zhang, Mayer, \& Hwang, 2018). Beyond these investigations, this result is parallel to a wealth of research that, whatever way, positive psychological resources relieve work stress (Bono et al., 2013; Kim \& Nam, 2018; Park et al., 2004; Peterson et al., 2009; Sherman et al., 2012).

Subsequently, the negative path from teachers' work stress to well-being is upheld by previous works (Park et al., 2004; Park et al., 2017; Peterson et al., 2009). The finding supports the position that work stress is on the opposite of well-being, even if well-being does not mean just a state without stress (Seligman, 2011). This evidence may be a natural outcome in that people highly perceiving work stress are less likely to feel well-being (Park et al., 2004; Park et al., 2017; Peterson et al., 2009).

The fourth path that goes from teachers' work motivation to well-being through the sequentially principal leadership and work stress was significant. As the part from work stress to well-being was discussed above, here, we will discuss just the part from work motivation to work stress through principal leadership. Out of it, the first part from work motivation to principal leadership showed a significant positive effect. The reason lies in that teachers with high work motivation have the likelihood of perceiving the principal leadership positively and seeking help, given investigations on work motivation (Bohns \& Flynn, 2010; Park et al., 2004; Peterson et al., 2009). Also, the fact that Korean elementary school teachers' calling is relatively high seems to act as a factor that teachers positively perceive the principal leadership (Jung, 2014). Moreover, considering the perspective of Coyle and Foti (2015), we can infer that since Korean elementary school teachers and principal go through much the same training course, dyadic partners show higher congruence on a leader or follower prototypes and, in turn, result in beneficial cooperation in the exchange relationship. 
The second part from principal leadership to work stress revealed the significant negative effect. This result seems to support the concept of prosocial motivation belonging to critical traits of leaders (Batson, 1987; Grant, 2008; Grant \& Berg, 2011), though there may be leaders hardly doing well such a role (Carton \& Lucas, 2017). Of course, the way that principals show prosocial motivation to relieve teachers' work stress can be diverse, ranging from suggesting goal orientation to showing a respect (Hendricks \& Payne, 2007; Huo \& Binning, 2008; Huo et al., 2010; O’Reilly et al., 2010; Schroeder \& Fishbach, 2015). Whatever way, after all, it seems that the higher teachers' perception of principal leadership, the lower their work stress, which arouses well-being.

Based upon discussion to date, we drew some implications as follows. First, this study deeply investigated major variables, which contribute to Korean elementary school teachers' well-being, and the relationships between them. Contrary to a substantial number of studies on early childhood teachers' well-being, there is a lack of studies on elementary school teachers' well-being. At this point, this study paved the way to understand elementary school teachers' well-being deeply by verifying microscopic relationships among work motivation, work stress, and principal leadership and well-being. Second, we identified a sequentially partial mediating effect of principal leadership and work stress on well-being. This finding will help us to consider delicate relationships between relevant variables when we need to develop a training program to promote elementary school teachers' well-being. Furthermore, we expect that the present work urges educational policymakers to build various plans to improve Korean elementary school teachers' well-being, which translates directly into students' well-being.

\section{Limitations and Future Directions}

Even though this study has important implications, it still has some limitations. Thus, we will provide some directions with limitations as follows.

First, a future study needs to perform the study which samples various participants including middle and high school teachers. In South Korea, since the system training elementary school teachers and middle and high school teachers differs from each other, the results of the present research cannot generalize to middle and high school teachers. By extension, this study is difficult to generalize to elementary school teachers in the different countries which have a different elementary school teacher training system.

Second, there is a need to use a scale encompassing different aspects of major variables. Above all, the instrument to measure work motivation needs to contain extrinsic work motivation which is suitable for the Korean situation. Of course, the Motivational Trait Questionnaire of Heggestad and Kanfer (2000) includes six sub-factors covering extrinsic work motivation. However, since the current study selected just two sub-factors such as a desire to learn and mastery goals appropriate for South Korean elementary school teachers, this research did not measure any extrinsic work motivation.

Besides, further study requires introducing the principal leadership scale embracing various kinds of leadership. The current work used the Authentic Leadership Scale developed by Avolio and Gardner (2005) to measure leadership. Afterward, it requires reflecting on the fact that results of the correlational analysis differed from each other depending upon the kinds of principal leadership sincerely (Lee \& Cho, 2017; Oh et al., 2015). After all, the reason that the third hypothesis, "Elementary school teachers' perception of principal leadership would have a partial mediating effect on their work motivation and well-being." was rejected might be due to the instrument assessing only authentic leadership.

\section{Conclusions}

There are growing numbers of investigations on early childhood teachers' well-being in South Korea. Conversely, it is still at a fledgling stage of discussing elementary school teachers' well-being despite the urgency. Facing this urgent situation, we performed this research to contribute to improving elementary school teachers' well-being in South Korea. Consequently, the current work concluded that it requires promoting elementary school teachers' work motivation and positive perception of principal leadership while reducing work stress, to enhance well-being. At this point, of course, there is a need to consider the delicate relationships among work motivation, the perception of principal leadership, and work stress, too. Therefore, when we need to develop a training program to enhance elementary school teachers' well-being, it would behoove us to consider their work motivation, the perception of principal leadership, work stress, and even the delicate relationships between them sincerely.

\section{References}

Anderson, J. C., \& Gerbing, D. W. (1988). Structural equation modeling in practice: A review and recommended two-step approach. Psychological bulletin, 103(3), 411-423. https://doi.org/10.1037/0033-2909.103.3.411

Avolio, B. J., \& Gardner, W. L. (2005). Authentic leadership development: Getting to the root of positive forms of leadership. The leadership quarterly, 16(3), 315-338. https://doi.org/10.1016/j.leaqua.2005.03.001 
Batson, C. D. (1987). Prosocial motivation: Is it ever truly altruistic? In L. Berkowitz (Ed.), Advances in experimental social psychology, 20 (pp. 65-122). NY: Academic Press. https://doi.org/10.1016/S0065-2601(08)60412-8

Bennett, A. A., Gabriel, A. S., Calderwood, C., Dahling, J. J., \& Trougakos, J. P. (2016). Better together? Examining profiles of employee recovery experiences. Journal of Applied Psychology, 101(12), 1635-1654. https://doi.org/10.1037/ap10000157

Bohns, V. K., \& Flynn, F. J. (2010). Why didn't you just ask? Underestimating the discomfort of help-seeking. Journal of Experimental Social Psychology, 46, 402-409. https://doi.org/10.1016/j.jesp.2009.12.015

Bono, J. E., Glomb, T. M., Shen, W., Kim, E., \& Koch, A. (2013). Building positive resources: Effects of positive events and positive reflection on work-stress and health. Academy of Management Journal, 56(6), 1601-1627. https://doi.org/10.5465/amj.2011.0272

Browne, M. W., \& Cudeck, R. (1993). Alternative ways of assessing model fit. In K. A. Bollen, \& J. Scott Long (Eds.), Testing structural equation models (pp. 1-9). CA: Sage.

Carton, A. M., \& Lucas, B. J. (2017). How can leaders overcome the blurry vision bias? An antidote to the paradox of vision communication. Academy of Management Journal [online]. https://doi.org/10.5465/amj.2015.0375

Chang, S., \& Koh, S. (2005). Development of the Korean occupational stress scale (KOSS). The Korean Journal of Stress Research, 13(3), 183-197.

Coyle, P. T., \& Foti, R. J. (2015). If you're not with me, you're...? The role of congruence and cooperation in leader-follower relationships. The Journal of Leadership and Organizational Studies, 22, 161-174. https://doi.org/10.5465/amj.2015.0375

Davis, J., \& Wilson, S. M. (2000). Principals' efforts to empower teachers: Effects on teacher motivation and job satisfaction and stress. The Clearing House, 73(6), 349-353. https://doi.org/10.1080/00098650009599442

Gillespie, J. Z. (2009). A humanistic viewpoint on use-inspired motivation research. Industrial and Organizational Psychology: Perspectives on Science and Practice, 2, 115-117. https://doi.org/10.1111/j.1754-9434.2008.01119.x

Grant, A. M. (2008). Does intrinsic motivation fuel the prosocial fire? Motivational synergy in predicting persistence, performance, and productivity. Journal of Applied Psychology, 93, 48-58. https://doi.org/10.1037/0021-9010.93.1.48

Grant, A. M., \& Berg, J. M. (2011). Prosocial motivation at work: When, why, and how making a difference makes a difference. In K. Cameron \& G. Spreitzer (Eds.), Oxford handbook of positive organizational scholarship (28-44). New York: Oxford University Press.

Grant, A. M., \& Shin, J. (2011). Work motivation: Directing, energizing, and maintaining effort (and research). In R. M. Ryan (Ed.), Oxford handbook of motivation. NY: Oxford University Press.

Heggestad, E. D., \& Kanfer, R. (2000). Individual differences in trait motivation: Development of the motivational trait questionnaire. International Journal of Educational Research, 33, 751-776. https://doi.org/10.1016/S0883-0355(00)00049-5

Hendricks, J. W., \& Payne, S. C. (2007). Beyond the Big Five: Leader goal orientation as a predictor of leadership effectiveness. Human Performance, 20(4), 317-343.

Hooper, D., Coughlan, J., \& Mullen, M. R. (2008). Structural equation modelling: Guidelines for determining model fit. Electronic Journal of Business Research Methods, 6(1), 53-60.

Huo, Y. J., \& Binning, K. R. (2008). Why the psychological experience of respect matters in group life: An integrative account. Social Psychology and Personality Compass, 2, 1570-1585. https://doi.org/10.1111/j.1751-9004.2008.00129.x

Huo, Y. J., Binning, K. R., \& Molina, L. E. (2010). Testing an integrative model of respect: Implications for social engagement and well-being. Personality and Social Psychology Bulletin, 36(2), 200-212. https://doi.org/10.1177/0146167209356787

Jung, K. (2014). A study on the enhancement of educators' professional teaching happiness: Main factors contributing to the commitment of Korean educators in previous research. The Journal of Korean Teacher Education, 31(3), 35-58. https://doi.org/10.24211/tjkte.2014.31.3.35

Kanfer, R. (2009). Work Motivation: Advancing Theory and Impact. Industrial and Organizational Psychology, 2(1), 118-127. http://doi.org/10.1111/j.1754-9434.2008.01120.x

Kern, M. L., Waters, L., Adler, A., \& White, M. (2014). Assessing employee wellbeing in schools using a multifaceted 
approach: Associations with physical health, life satisfaction, and professional thriving. Psychology, 5, 500-513. https://doi.org/10.4236/psych.2014.56060

Kim, H., \& Nam, S. (2018). The effects of positive psychology capital on job stress and organizational commitment: Mediating effect of happiness. Asia-pacific Journal of Multimedia Services Convergent with Art, Humanities, and Sociology, 8(3), 553-561.

Kim, S., Park, Y., \& Niu, Q. (2017). Micro-break activities at work to recover from daily work demands. Journal of Organizational Behavior, 38, 28-44. https://doi.org/10.1002/job.2109

Korean Educational Development Institute. (2017). Educational statistics analysis: K-12 educational Statistics. Sejong: Korean Ministry of Education.

Kwon, S. (2012). Structural relationship among kindergarten director's transformational leadership and preschool teacher's job satisfaction: Focused on the mediating effects of teacher-efficacy, job stress, and organizational commitment (Doctoral dissertation). Retrieved from http://yu.dcollection.net/public_resource/pdf/000001566538_20180916211756.pdf

Lee, K., \& Cho, E. (2017). The relationship among director's servant leadership perceived by early childhood teachers, teaching flow and happiness. Korean Journal of Childcare and Education, 13(1), 65-83.

Lee, M., Kim, K., \& Kim, T. (2017). The relationship between vocational calling and psychological wellbeing of elementary school teachers: The mediating effects of resilience. Korean Journal of Elementary Education, 28(4), 215-229. https://doi.org/10.20972/kjee.28.4.201712.215

Lee, Y. (2012). The relationships of ego resilience, social supports, and the psychological burn-out of the female teachers of the elementary school. The Journal of Elementary Education, 25(1), 191-214.

Nie, Y., Chua, B. L., Yeung, A. S., Ryan, R. M., \& Chan, W. Y. (2015). The importance of autonomy support and the mediating role of work motivation for well-being: Testing self-determination theory in a Chinese work organization. International Journal of Psychology, 50(4), 245-255. https://doi.org/10.1002/ijop.12110

O'Reilly, C., Caldwell, D., Chatman, J., Lapiz, M., \& Self, W. (2010). How leadership matters: The effects of leadership alignment on strategic execution. The Leadership Quarterly, 21(1), 104-113.

https://doi.org/10.1016/j.leaqua.2009.10.008

Oh, S., Roh, S., Kang, M., \& Suh, Y. (2015). Resilience as a mediator linking transformational leadership and person-centered organizational culture to organizational effectiveness. The Korean Journal of Industrial and Organizational Psychology, 28(4), 829-854. https://doi.org/10.24230/ksiop.28.4.201511.829

Park, N., Peterson, C., \& Seligman, M. E. P. (2004). Strengths of character and well-being. Journal of Social and Clinical Psychology, 23, 603-619. https://doi.org/10.1521/jscp.23.5.603.50748

Park, S., Son, E. (2011). Factors of psychological well-being and the relations with psychological well-being, teacher efficacy, job satisfaction in elementary school female teachers. Korean Journal of Teacher Education, 27(3), 151-166.

Park, Y., Bruno, R., \& Headrick, L. (2017). Elementary teachers' work-related stressors and strain outcomes. Illinois Education Association and Illinois Federation of Teachers.

Peterson, C., Park, N., Hall, N., \& Seligman, M. E. P. (2009). Zest and work. Journal of Organizational Behavior, 30, 161-172. https://doi.org/10.1002/job.584

Schroeder, J., \& Fishbach, A. (2015). How to motivate yourself and others? Intended and unintended consequences. Research in Organizational Behavior, 35, 123-141. https://doi.org/10.1016/j.riob.2015.09.001

Seligman, M. E. P. (2011). Flourish. New York: Simon \& Schuster.

Sherman, G. D., Lee, J. J., Cuddy, A. J. C., Renshon, J., Oveis, C., Gross, J. J., \& Lerner, J. S. (2012). Leadership is associated with lower levels of stress. Proceedings of the National Academy of Sciences, 109(44), 17903-17907. https://doi.org/10.1073/pnas.1207042109

Shin, H. (2018). 936 cases of sexual violence discussions in elementary school last year...Seven-fold rapid increase in five years. Edaily. Retrieved from http://www.edaily.co.kr/news/read?newsid=02443606619341432\&mediaCodeNo=257\&OutLnkChk=Y

Wang, W., Hernandez, I., Newman, D. A., He, J., \& Bian, J. (2016). Twitter analysis: Studying US weekly trends in work stress and emotion. Applied Psychology: An International Review, 65(2), 355-378. https://doi.org/10.1111/apps.12065 
Wolf, E. B., Lee, J. J., Sah, S., \& Brooks, A. W. (2016). Managing perceptions of distress at work: Reframing emotion as passion. Organizational Behavior and Human Decision Processes 137, 1-12. https://doi.org/10.1016/j.obhdp.2016.07.003

Wrzesniewski, A., McCauley, C. R., Rozin, P., \& Schwartz, B. (1997). Jobs, careers, and callings: People's relations to their work. Journal of Research in Personality, 31, 21-33. https://doi.org/10.1006/jrpe.1997.2162

Zhang, C., Mayer, D. M., \& Hwang, E. (2018). More is less: Learning but not relaxing buffers deviance under job stressors. Journal of Applied Psychology, 103(1), 123-136. https://doi.org/10.1037/ap10000264

\section{Copyrights}

Copyright for this article is retained by the author(s), with first publication rights granted to the journal.

This is an open-access article distributed under the terms and conditions of the Creative Commons Attribution license which permits unrestricted use, distribution, and reproduction in any medium, provided the original work is properly cited. 